\title{
Call for reviews on global health challenges
}

\author{
Peiling Yap $\cdot$ Peter Waiswa $\cdot$ Anke Berger $\cdot$ Nino Künzli
}

Received: 14 August 2015/Accepted: 17 August 2015/Published online: 1 September 2015

(C) Swiss School of Public Health 2015

It is our great pleasure to publish this special issue with reviews relevant to global health. IJPH launched this Call to concert the 9th European Congress on Tropical Medicine and International Health, which runs under the title "Driving the Best Science to Meet Global Health Challenges". The Call received high attention with 18 manuscripts submitted from 11 countries in the Americas, Europe and Asia. Although half of the submitted reviews addressed problems in low-income or developing countries, no authors from Africa responded to the Call. Does

This editorial is part of the special issue "Driving the Best Science to Meet Global Health Challenges" edited on the occasion of the 9th European Congress on Tropical Medicine and International Health 2015.

P. Yap · N. Künzli $(\bowtie)$

Swiss Tropical and Public Health Institute, Socinstrasse 57, P.O. Box, 4002 Basel, Switzerland

e-mail: nino.kuenzli@unibas.ch

P. Yap · N. Künzli

University of Basel, Basel, Switzerland

P. Waiswa

Maternal and Newborn Centre of Excellency,

Makerere University, Kampala, Uganda

P. Waiswa

Division of Global Health, Karolinska Institutet, Stockholm, Sweden

\section{A. Berger}

University of Bern, Institute of Social and Preventive Medicine

University, Bern, Switzerland

N. Künzli

Swiss School of Public Health (SSPH+), Zurich, Switzerland this reflect the continued inequity in the availability of research resources for global health?

To manage the rigorous peer review process, we were again largely dependent on our highly committed international reviewers, greatly acknowledged in Table 1 . Given the topic of the Call, we tried our best to involve experts from across the world as peer reviewers and received reports from 37 experts from 16 countries, though the majority of peer reviewers is based in USA or Canada (13), or in Europe (12). Nine reviews were finally accepted for publication. The special issue now presents an interesting range of reviews, as the contributing authors bring to our focus infectious diseases, maternal and child health, and finally physical and mental health.

Repeating the major success of the IJPH Call launched in 2013 (Künzli 2013), we have again asked the audience of the conference to choose the most interesting review based on a set of four abstracts that we considered to represent the most relevant reviews that were accepted for publication. The four publications reviewed topics on equity in maternal health care service utilization, knowledge transfer strategies to improve public health in lowincome countries, injury and rehabilitation interventions in humanitarian crises and concerns on vaccination use in low- and middle-income countries.

Reducing maternal mortality is one of the Millennium Development Goals (MDGs) and in the post-2015 era, it will remain an important agenda to be pursued amidst the achievement of the Sustainable Development Goals (SDGs). A systematic review by Çalışkan et al. (2015) found a lack of equity in the utilization of maternal health care in developing countries, and directed our attention to not only improving maternal care but more importantly, ensuring that even the most disadvantaged mothers have equal access to the improved care. This is an important 
Table 1 The following 37 scientists contributed to the peer review process of the IJPH Call for reviews on global health (alphabetical order)

Laith J. Abu-Raddad (Qatar), Patricia Angeleri (Argentina), Anne-Marie Boulay (Canada), Heather Brown (UK), Stephanie Burrows (Canada), Pedro Cahn (Argentina), Michael Clarke (UK), Claudia Daubenberger (Switzerland), Peter Ekamper (Netherlands), Michael Favin (USA), Atle Fretheim (Norway), Melissa Gladstone (UK), Jim Gosney (USA), Sophie Goyet (France), Pedro Hallal (Brazil), Ayako Honda (South Africa), Richard Idro (Uganda), David E. Jacobs (USA), Mollie Kile (USA), Hanneke Kruize (Netherlands), Nino Künzli (IJPH Co-Editor-in-Chief, Switzerland), David LaPlante (Canada), Mary E. Miller (USA), Chris Morgan (Australia), Juliet Nabyonga (Uganda), Marisa F. Naujokas (USA), Hung Nguyen-Viet (Vietnam), Maria A. Pando (Argentina), Stephane Perron (Canada), Gurleen Popli (UK) Kimberly Rauscher (USA), W. Evan Secor (USA), Katarina Stete (Germany), Paul Ananth Tambyah (Singapore), Simoni Triantafyllidou (USA), Peter Waiswa (IJPH Editor, Uganda), Peiling Yap (IJPH Guest-Editor, Switzerland)

paradigm shift, which will bring us another step closer to reducing maternal mortality.

Knowledge transfer from research to policy and use is an interesting and important process for the global health community. Through a scoping review, Dagenais et al. (2015) provided an overview of the effective and innovative transfer strategies commonly employed and highlighted the need for a systematic evaluation of these strategies. A well-established knowledge transfer process is also essential to inform injury and physical rehabilitation interventions in times of conflict and environmental disasters. As Smith et al. (2015) reviewed the quality of evidence that informs rehabilitation interventions in humanitarian crises, they discovered an inadequacy of such evidence with most of the existing evidence being of mediocre quality. They also highlighted the need to bridge the gap between the research and operational communities. It is often said that knowledge is power and as illustrated in these two publications, ensuring a quick and effective transfer of knowledge from research to public use will allow the empowerment of health care consumers and humanitarians.

Vaccine hesitancy is a phenomenon increasingly observed in both developing and developed countries. Bosch-Caplanch et al. (2015) highlighted that concerns on the harmful effects of vaccination turned out to be the most common factor influencing vaccine use in developing countries. Although a lot of research has been performed describing concerns on vaccine use, studies testing interventions to address these concerns are scarce. Since vaccine use is highly influenced by social, cultural and religious beliefs, developing a package of interventions addressing each concern might prove to be more useful for the global community.
With the conclusion of the voting period, we are pleased to announce that the runner-up of the award competition is the review of Caliskan and colleagues with 49 out of 235 votes - congratulations to the authors! With 112 out of 235 votes, the review of Cobos Muñoz and co-authors emerged a clear winner. We congratulate and gladly award the first author with free open access publication of the review and a sum 2'000 CHF.

We hope that our readers are intrigued by the reviews published in this issue and that all those being at the conference in Basel will greatly profit from this scientific platform on global health.

\section{References}

Çalışkan Z, Dilek Kılıç D, Öztürk S, Atılgan E (2015) Equity in maternal health care service utilization: a systematic review for developing countries. Int J Public Health 60(7). doi:10.1007/ s00038-015-0711-x

Cobos Muñoz D, Monzón Llamas L, Bosch-Capblanch X (2015) Exposing concerns about vaccination in low and middle income countries: a systematic review. Int J Public Health 60(7). doi:10. 1007/s00038-015-0715-6

Dagenais C, Siron S, Ridde V (2015) What research tells us about knowledge transfer strategies to improve public health in lowincome countries: a scoping review. Int J Public Health 60(7). doi: 10.1007/s00038-015-0716-5

Künzli N (2013) IJPH goes environmental: does it? Int J Public Health 58(5):643-644

Smith J, Roberts B, Knight A, Gosselin R, Blanchet K (2015) A systematic literature review of the quality of evidence for injury and rehabilitation interventions in humanitarian crises. Int $\mathrm{J}$ Public Health 60(7). doi:10.1007/s00038-015-0723-6 